\title{
Study of the Efficacy of Triple Therapy of Sofosbuvir, Pegylated INFalpha 2a and Ribavirin in Treatment of Chronic Hepatitis C Patients Genotype 4 with High Fibrosis
}

\author{
Alaa Aboud \\ Department of Tropical Medicine, Benisuef University Faculty of Medicine, Benisuef, Egypt \\ Email: Dralaaboud2005@yahoo.com
}

How to cite this paper: Aboud, A. (2017) Study of the Efficacy of Triple Therapy of Sofosbuvir, Pegylated INFalpha 2a and Ribavirin in Treatment of Chronic Hepatitis C Patients Genotype 4 with High Fibrosis. Open Journal of Gastroenterology, 7, 517.

http://dx.doi.org/10.4236/ojgas.2017.71002

Received: November 20, 2016

Accepted: January 8, 2017

Published: January 11, 2017

Copyright $\odot 2017$ by author and Scientific Research Publishing Inc. This work is licensed under the Creative Commons Attribution International License (CC BY 4.0).

http://creativecommons.org/licenses/by/4.0/

\begin{abstract}
Purpose: The aim is evaluation of the efficacy of triple therapy of sofosbuvir, pegylated INFalpha $2 \mathrm{a}$ and ribavirin in treatment of chronic hepatitis $\mathrm{C}$ (CHC) patients genotype 4 who have high fibrosis. Materials and Methods: Fifty HCV patients with high fibrosis (F3 \& F4) were included in the study. Results: SVR rate was 54\%; non-responders rate was $12 \%$ and relapsers rate was $34 \%$. When comparing SVR between F3 group patients and F4 group, it was $88 \%$ and $66 \%$ respectively, which means that SVR was higher in the F3 group. Conclusion: Triple therapy including pegylated INFalpha $2 \mathrm{a}$ is not an ideal therapy in treatment of CHC patients genotype 4 with cirrhosis because of low sustained virological response rates and high incidence of side effects.
\end{abstract}

\section{Keywords}

Chronic Hepatitis C, Sofosbuvir, Pegylated INF, Ribavirin

\section{Introduction}

HCV currently infects nearly $2 \%$ of the world's population. In Egypt the situation has been considered actually critical. Hepatitis $\mathrm{C}$ virus seems to be one of the major health problems in Egypt which have the highest prevalence in the world. Nowhere else is there an HCV epidemic that affects a whole country. In all other countries, the prevalence of $\mathrm{HCV}$ is between $1 \%$ and $2 \%$. There are a few exceptions where the prevalence of $\mathrm{HCV}$ is 3\%. In Egypt however, the prevalence of HCV is $14.7 \%$. Hepatitis C virus affects most families in Egypt. HCV has high rates of spread as it can infect at least 1 in 10 of the population aged 15 to 59 and mortality rates in Egypt are about 40,000 per year [1]. 
$\mathrm{HCV}$ genotype 4 which is considered major problem in Egypt started to appear in increased manner in several regions in Europe due to immigration and injection drug users treatment of this genotype with conventional interferons was low. The introduction of combined pegylated interferon and ribavirin increased SVR to about $60 \%$. And it is still difficult in certain situations such as the presence of HCV-4 non-responders, injection drug users, patients coinfected with human immunodeficiency virus, thalassaemic patients, patients on hemodialysis and patients with $\mathrm{HCV}-4$ recurrence after liver transplantation still represents a significant therapeutic challenge. Introduction of direct acting antiviral agents has greatly improved success rates in management of patients with $\mathrm{HCV}-4$ and created a great hope for many patients who are suffering from hepatitis $\mathrm{C}$ virus complications [2].

Chronic hepatitis $\mathrm{C}$ causes significant morbidity which interferes with health economics. Chronic form of hepatitis C represents about $75 \%$ and although it is usually asymptomatic, progression to cirrhosis is not uncommon. And also complications of cirrhosis, including ascites, hepatic encephalopathy and esophageal varices, all represent major obstacles in patients of HCV. Over a period of 20 years, it is estimated that $10 \%-15 \%$ of $\mathrm{CHC}$ patients eventually develop cirrhosis. Of these, an estimated 1\% - 4\% of patients develop HCC [3].

Esophageal variceal bleeding is one of the most serious complications due to high mortality with high prevalence of varices in cirrhotic patients about $60 \%$ $80 \%$ and risk of bleeding about $25 \%-35 \%$ [3].

Development of new DAAs including Sofosbuvir allowed the availability of triple therapy which has improved SVR in naïve patients and treatment experienced patients. but response rates were still unsatisfactory in cirrhotic patients. It has been clear in diagnosed HCV patients that approximately $20 \%$ actually commence treatment and only $3 \%-4 \%$ of the total diagnosed population achieves SVR. Recent regimens are also associated with a range of limitations including long and complex treatment regimens, severe side-effects that have led to treatment discontinuations in $(>20 \%-30 \%)$, and the development of treatment-resistant viral mutations, all of which can lead to treatment failure. Thus, there is a clear medical need for more effective pan-genotypic regimens with a high barrier to resistance without drug-to-drug interactions that would enable a broader population of patients' possibility of cure [3].

Sofosbuvir is one of the DAAs, which is inhibitor of HCV NS5B RNA dependent polymerase that suppresses viral replication, and also is included in combination therapies of treatment of $\mathrm{HCV}$, and also has the advantage of being pan genotypic, and has high genetic barrier.

This study aims to evaluate the efficacy of triple therapy of sofosbuvir, pegylated INFalpha $2 \mathrm{a}$ and ribavirin in treatment of chronic hepatitis $\mathrm{C}$ patients genotype 4 with high fibrosis (F3-F4).

\section{Materials and Methods}

This study is conducted in Tropical Medicine and Gastroenterology Department, Faculty of Medicine, Benisuef University from May 2015 to January 2016 
after approval by the local ethics committee. Fifty patients who have chronic HCV infection were included in the study (13 females and 37 males) after obtaining their informed written consent; patients were selected from patients visiting HCV treatment units for pretreatment evaluation.

All patients met the following inclusion criteria: chronic infection with HCV according to seropositivity for anti-HCV antibodies, age of at least 18 years, $\mathrm{Hb}$ level of at least $12 \mathrm{~g} / \mathrm{dL}$, compensated liver disease, and no hepatocellular carcinoma.

Exclusion criteria were as follows: Liver cell failure, HBV co-infection, significant cardiovascular, uncontrolled hypertension, uncontrolled diabetes, renal, hematologic, neurologic, or psychiatric disease thyroid disorders and autoimmune disorders.

All patients were subjected to:

- Proper history and thorough clinical examination.

- The following laboratory tests: complete blood count, liver function tests, coagulation profile, kidney function tests, thyroid function tests, quantitative polymerase chain reaction for HCV RNA (real-time technique), fasting blood glucose level.

- Fundus examination of the eyes.

- Pelvi-abdominal ultrasonography

- Upper endoscopy in cirrhotic patients.

- Liver biopsy.

All patients received pegylated INF alpha 2a 180 ug once per week, sofosbuvir $400 \mathrm{mg}$ once daily and ribavirin guided by weight of patients those less than 75 kilos receive $1000 \mathrm{mg}$ daily and those more than 75 kilos dose is $1200 \mathrm{mg}$ daily for 12 weeks.

Patients follow-up

1-After 4 weeks: Complete blood count, liver function tests and PCR done.

2-8 weeks: liver function tests as well as hemoglobin, Total leukocyte count and platelets done.

3-12 weeks: CBC and LFTs were performed for all patients in addition to quantitative PCR for HCV RNA and AFP.

4-3 months following treatment $\mathrm{CBC}$, liver profile, AFP and PCR was repeated for all patients.

- Non-responders: detectable HCVRNA in the serum at the end of treatment.

- Relapser: undetectable HCVRNA in the serum at the end of treatment then subsequently return to be detected.

Sustained virological response (SVR) 12: means that HCVRNA become undetectable at the end of follow up.

Ethical considerations

The protocol was approved by the local ethics committee in our faculty, and all patients gave their written informed consent before being included in the study.

Statistical analysis: 
The data will be collected using the Statistical Package for Social Science (SPSS) version 17. Data were statistically described in terms of mean, standard deviation frequencies (number of cases) and relative frequencies (percentages) when appropriate. To compared with a paired student's $t$ test, the significance of non-parametric data will be determined using chi-square test.

$P$. The probability/significance value.

$P$ value $>0.05$ (NS) Not significant.

$P$ value $<0.05^{\star}$ Significant at 0.05 level.

$P$ value $<0.01^{\star *}$ Significant at 0.01 Level.

\section{Results}

This study was conducted in Tropical Medicine and Gastroenterology Department, Faculty of Medicine, Benisuef University from May 2015 to May 2016 after approval by the local ethics committee. Fifty patients whom have chronic HCV infection were included in this study (13 females and 37 males) after obtaining their informed written consent.

The demographic features of the studied 50 patients are shown in Table 1 and revealed that the age of the studied patients; ranged between 40 and 69 years with a mean of 53.5 years and standard deviation (SD) of 5.7.

Also it shows that 37 patients (74\%) were males, and 13 patients (26\%) were females (Figure 1(a)).

Table 1. Clinical data in all patients.

\begin{tabular}{cc}
\hline & No. (\%) \\
Age (Year) & $40-69$ \\
Sex, no. (\%) & $53.5 \pm 5.7$ \\
Male & $37(74)$ \\
Female & $13(26)$ \\
Risk, no. (\%) & \\
No & $13(26)$ \\
Previous operation & $15(30)$ \\
Antischistosomal injections & $21(42)$ \\
Previous operation and antischistosomal injections & $1(2)$ \\
Bleeding tendency, no. (\%) & $23(46)$ \\
Lower limb edema, no. (\%) & $5(10)$ \\
Hematemesis, no. (\%) & $1(2)$ \\
Jaundice, no. (\%) & $0(0)$ \\
Ascites, no. (\%) & $0(0)$ \\
Liver by exam, no. (\%) & $0(0)$ \\
Spleen by exam, no. (\%) & $5(10)$ \\
Spider naevi, no. (\%) & $1(2)$ \\
History of hepatic encephalopathy, no. (\%) & $31(62)$ \\
\hline
\end{tabular}




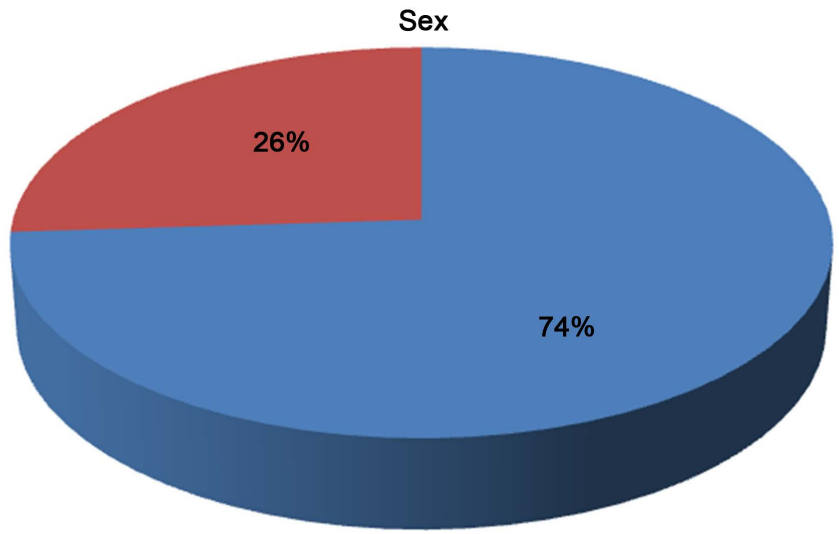

Male

Female

(a)

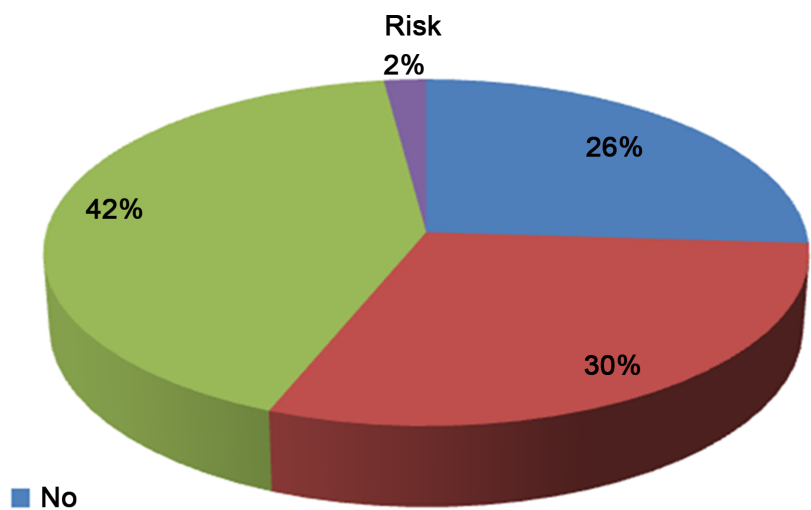

- Previous operation

Anrtischistosomal injections

- Previous operation and anrtischistosomal injections

(b)

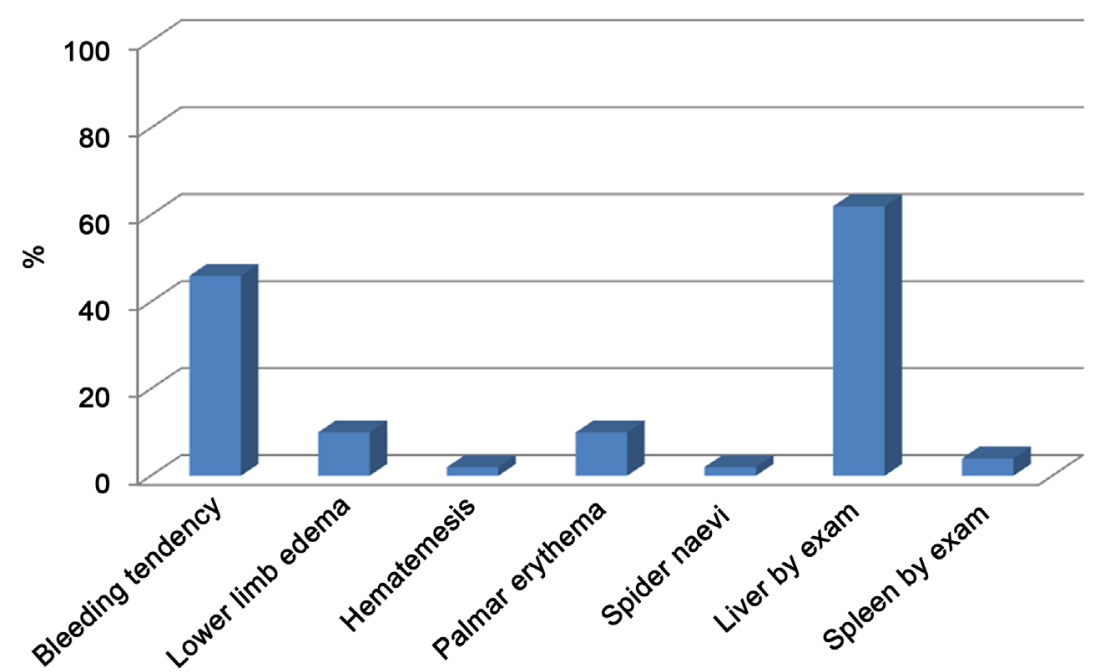

(c)

Figure 1. (a) Shows sex distribution of the studied patients; (b) shows risk factors of HCV in the studied patients; (c) shows clinical presentation and examination of studied patients. 
According to the risk factors 21 patients (42\%) was due to antischistosomal injections, 15 patients (30\%) due to previous operations, 13 patients (26\%) with no obvious risk factor and one patient (2\%) was due combined antischistosomal injections and previous operations (Figure 1(b)).

According to the stage of fibrosis 33 patients (66\%) was F4 and 17 patients (34\%) was F3 as shown in Table 2 and Figure 2(a).

Clinical examination of the studied patients in Table 1 and Figure 1 (c) shows that Bleeding tendency was 46\% Lower limb Edema was 10\%; Palmar Erythema was $10 \%$ Spider naevi was $2 \%$; hematemesis was $2 \%$ and there was no jaundice,

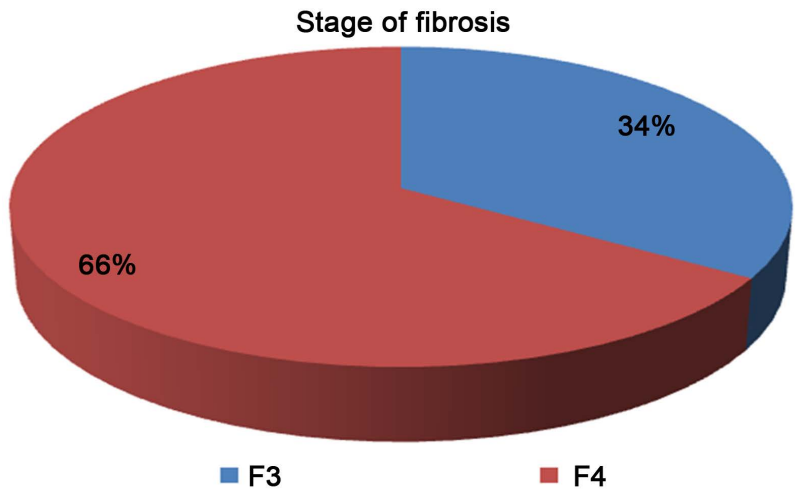

(a)

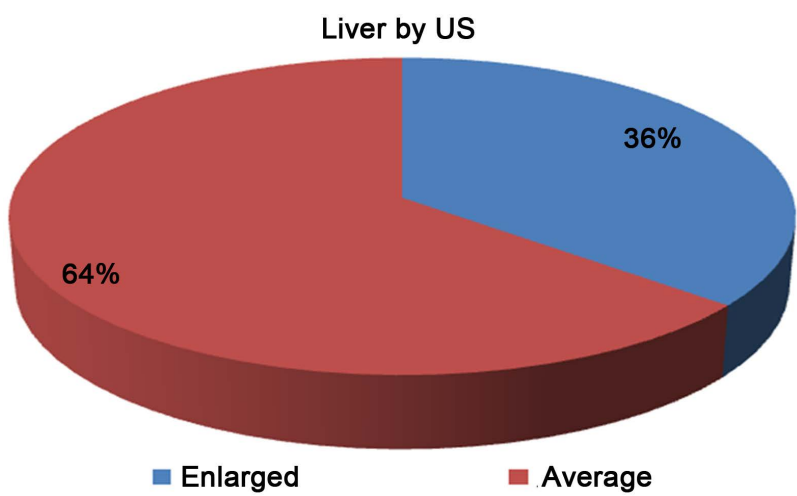

(b)

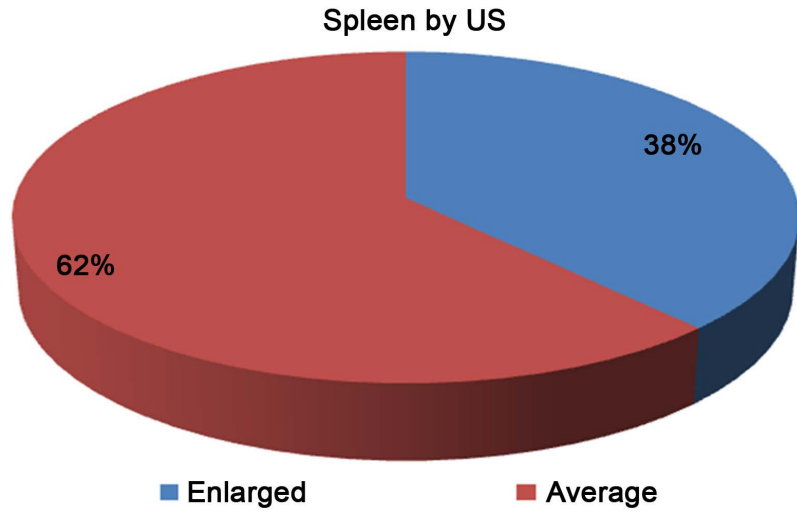

(c)

Figure 2. (a) Shows stage of fibrosis in the studied patients; (b) shows liver size by ultrasonography; (c) shows spleen size by ultrasonography. 
Table 2. US findings and stage of fibrosis in all patients.

\begin{tabular}{cc}
\hline & No. (\%) \\
Stage of fibrosis, no. (\%) & $17(34)$ \\
F4 & $33(66)$ \\
Liver by US, no. (\%) & $18(36)$ \\
Enlarged & $32(64)$ \\
Average & $19(38)$ \\
Spleen by US, no. (\%) & $31(62)$ \\
Enlarged & $0(0)$ \\
Average & $8-17$ \\
Ascites by US, no. (\%) & $12.7 \pm 2.3$ \\
\hline PV diameter mm (N TO 12MM) & \\
\hline
\end{tabular}

no ascites and no history of hepatic encephalopathy. Liver was detected in $62 \%$ of patients while spleen was palpable in $4 \%$.

Abdominal ultrasound assessment of the liver described that the liver size was average in 32 patients (64\%), enlarged in 18 patients (36\%) as shown in Table 2 and Figure 2(b). Abdominal ultrasound assessment of the splenic size by measuring the splenic longest axis it is clear that the splenic longest axis was average in size (up to $12-13 \mathrm{~cm}$ ) in 31 patients (62\%). Splenomegaly was detected in 19 patients (38\%) as shown in Table 2 and Figure 2(c).

There was no ascites in any of the patients as shown in Table 2. As regard degree of viremia 19 patients has mild viremia, 28 have moderate viremia and 3 have high viremia as shown in Table 3 and Figure 3.

There was no significant change before, during and after treatment as regard Bilirubin, fasting blood sugar, creatinine, albumin, thyroid stimulating hormone and alpha feto protein but there was significant change as regard liver enzymes with normalization of alanine aminotransferase and aspartate aminotransferase post treatment as shown in Table 4 and Figure 4(a).

As regard complete blood count there was significant anemia, leucopenia due to treatment but there was no significant change as regard platelets count as shown in Table 4 and Figures 4(b)-(d).

As regard side effects, flu like symptoms were the most predominant followed by pruritus, cough and the least observed was dyspepsia and this is shown in Table 5 and Figure 5.

Sustained virological response rate was higher in patients with stage 3 fibrosis than in cirrhotic patients as shown in Table 6 and Figure 6.

Sustained virological response rates 12 weeks after end of treatment was 54\%, non-responder rate was $12 \%$ and relapser rate was $34 \%$ as shown in Table 7 and Figure 7. 
Table 3. Degree of viremia in all patients.

\begin{tabular}{cccc}
\hline & Before ttt & Degree of viremia & Patients $(\mathrm{n}=50)$ \\
\hline PCR & & Mild, no. (\%) & $19(38)$ \\
Range & $1300-1,871,969$ & Moderate, no. (\%) & $28(56)$ \\
Mean \pm SD & $293433.9 \pm 357730.6$ & High, no. (\%) & $3(6)$ \\
\hline
\end{tabular}

Table 4. Comparison between before and after ttt as regarding liver function test.

\begin{tabular}{|c|c|c|c|c|c|c|}
\hline & \multicolumn{5}{|c|}{ Treatment } & \multirow{2}{*}{$P$ value } \\
\hline & Before & 4 weeks & 8 weeks & 12 weeks & 3 months & \\
\hline Bilirubin, no. (\%) & $12(24)$ & $5(10)$ & $10(20)$ & $10(20)$ & $6(13.6)$ & $\begin{array}{l}\mathrm{P} 1=0.108 \\
\mathrm{P} 2=0.809 \\
\mathrm{P} 3=0.809 \\
\mathrm{P} 4=0.192\end{array}$ \\
\hline Albumin, no. (\%) & $5(10)$ & $5(10)$ & $4(8)$ & $6(12)$ & $5(11.4)$ & $\begin{array}{c}\mathrm{P} 1=1 \\
\mathrm{P} 2=0.999 \\
\mathrm{P} 3=0.998 \\
\mathrm{P} 4=1\end{array}$ \\
\hline PT, no. (\%) & $6(12)$ & $4(8)$ & $6(12.2)$ & $6(12)$ & $7(15.9)$ & $\begin{array}{c}\mathrm{P} 1=0.740 \\
\mathrm{P} 2=1 \\
\mathrm{P} 3=1 \\
\mathrm{P} 4=0.998\end{array}$ \\
\hline Hb, no. (\%) & $10(20)$ & $31(62)$ & $38(76)$ & $38(76)$ & $16(32)$ & $\begin{aligned} \mathrm{P} 1 & =0.001^{* *} \\
\mathrm{P} 2 & =0.001^{* *} \\
\mathrm{P} 3 & =0.001^{* *} \\
\mathrm{P} 4 & =0.254\end{aligned}$ \\
\hline WBCs, no. (\%) & $7(14)$ & $19(38)$ & $20(40)$ & $20(40)$ & $10(22.7)$ & $\begin{aligned} \mathrm{P} 1 & =0.011^{*} \\
\mathrm{P} 2 & =0.006^{* *} \\
\mathrm{P} 3 & =0.006^{* *} \\
\mathrm{P} 4 & =0.595\end{aligned}$ \\
\hline PLT, no. (\%) & $23(46)$ & $24(48)$ & $30(60)$ & $25(50)$ & $17(38.6)$ & $\begin{array}{l}\mathrm{P} 1=0.998 \\
\mathrm{P} 2=0.229 \\
\mathrm{P} 3=0.841 \\
\mathrm{P} 4=0.307\end{array}$ \\
\hline Creatinine, no. (\%) & $14(28)$ & $17(34)$ & $16(32)$ & $15(30)$ & $13(29.5)$ & $\begin{array}{l}\mathrm{P} 1=0.665 \\
\mathrm{P} 2=0.827 \\
\mathrm{P} 3=0.998 \\
\mathrm{P} 4=0.998\end{array}$ \\
\hline ALT & $42(84)$ & $23(46)$ & $18(36)$ & $11(22)$ & $8(16)$ & $\begin{array}{l}\mathrm{P} 1=0.001^{* \star} \\
\mathrm{P} 2=0.001^{\star \star} \\
\mathrm{P} 3=0.001^{\star *} \\
\mathrm{P} 4=0.001^{* \star}\end{array}$ \\
\hline AST & $41(82)$ & $29(58)$ & $20(40)$ & $12(24)$ & $10(20)$ & $\begin{array}{l}\mathrm{P} 1=0.015^{*} \\
\mathrm{P} 2=0.001^{* *} \\
\mathrm{P} 3=0.001^{* *} \\
\mathrm{P} 4=0.001^{* *}\end{array}$ \\
\hline FBS, no. (\%) & $5(10)$ & - & - & - & - & - \\
\hline TSH, no. (\%) & $0(0)$ & $0(0)$ & - & $0(0)$ & $0(0)$ & - \\
\hline AFP, no. (\%) & $15(30)$ & - & - & $15(30.6)$ & $13(29.5)$ & $\begin{array}{c}\text { P3 }=1 \\
\text { P4 }=0.824\end{array}$ \\
\hline
\end{tabular}

P1: Comparison between before and after 4 weeks ttt; P2: Comparison between before and after 8 weeks ttt; P3: Comparison between before and after 12 weeks ttt; P4: Comparison between before and after 3 months ttt. 


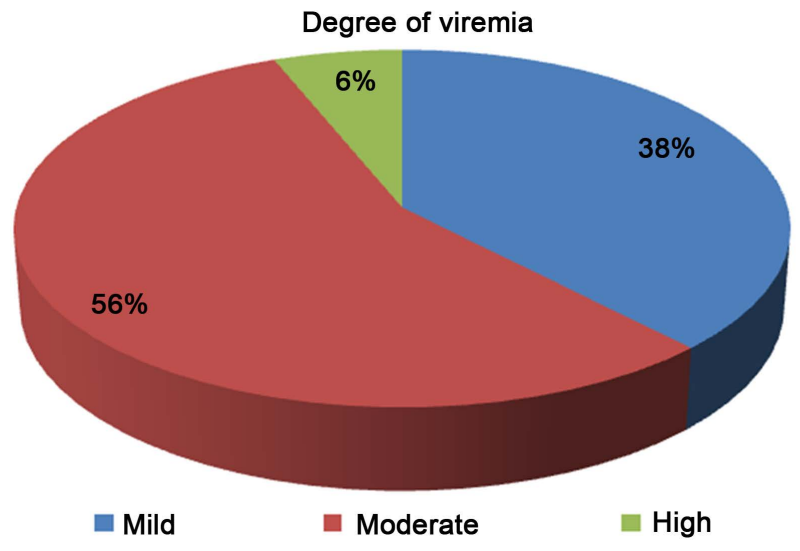

Figure 3. Shows degree of viremia.

Table 5. Side effects during treatment.

\begin{tabular}{|c|c|c|c|c|c|}
\hline & \multicolumn{5}{|c|}{ Treatment } \\
\hline & Before & 4 weeks & 8 weeks & 12 weeks & 3 months \\
\hline Side effect, no. (\%) & & & & & - \\
\hline - No & - & $16(32)$ & $31(62)$ & $47(94)$ & \\
\hline - Flu like symptoms & & $31(62)$ & $6(12)$ & $0(0)$ & \\
\hline - Pruritus & & $3(6)$ & $5(10)$ & $1(2)$ & \\
\hline - Cough & & $0(0)$ & $6(12)$ & $1(2)$ & \\
\hline - GIT troubles & & $0(0)$ & $2(4)$ & $1(2)$ & \\
\hline
\end{tabular}

Table 6. Correlation between response to treatment and stage of fibrosis at different times.

\begin{tabular}{cccccc}
\hline \multirow{2}{*}{ Stage of fibrosis } & \multicolumn{5}{c}{ PCR } \\
\cline { 2 - 6 } & Before & 4 weeks & 8 weeks & 12 weeks & 3 months \\
\hline No, no. (\%) & $0(0)$ & $50(100)$ & $50(100)$ & $44(88)$ & $33(66)$ \\
F3, no. (\%) & $17(34)$ & $0(0)$ & $0(0)$ & $2(4)$ & $4(8)$ \\
F4, no. (\%) & $33(66)$ & $0(0)$ & $0(0)$ & $4(8)$ & $13(26)$ \\
$P$ value & - & - & - & $0.001^{* *}$ & $0.001^{* *}$ \\
\hline
\end{tabular}

Table 7. Sustained virological response rate, non-responders and relapser after treatment.

\begin{tabular}{|c|c|c|c|c|c|c|}
\hline & \multicolumn{5}{|c|}{ Treatment } & \multirow{2}{*}{$P$ value } \\
\hline & Before & 4 weeks & 8 weeks & 12 weeks & 3 months & \\
\hline \multirow[t]{2}{*}{ PCR, no. (\%) } & $50(100)$ & - & - & $6(12)$ & $17(34)$ & $\begin{array}{l}\mathrm{P} 3=0.001^{\star *} \\
\mathrm{P} 4=0.001^{\star *}\end{array}$ \\
\hline & & SVR & \multicolumn{3}{|c|}{ Non responsive } & Relapse \\
\hline \multicolumn{2}{|c|}{ PCR, no. (\%) } & $27(54)$ & \multicolumn{3}{|c|}{$6(12)$} & $17(34)$ \\
\hline
\end{tabular}




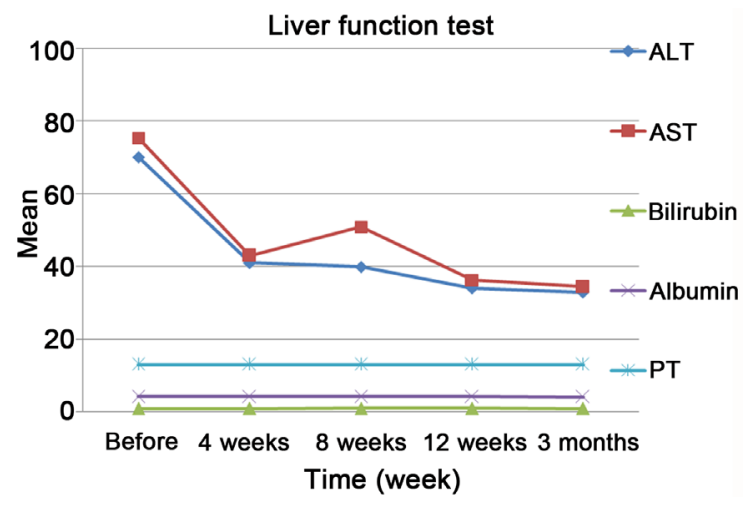

(a)

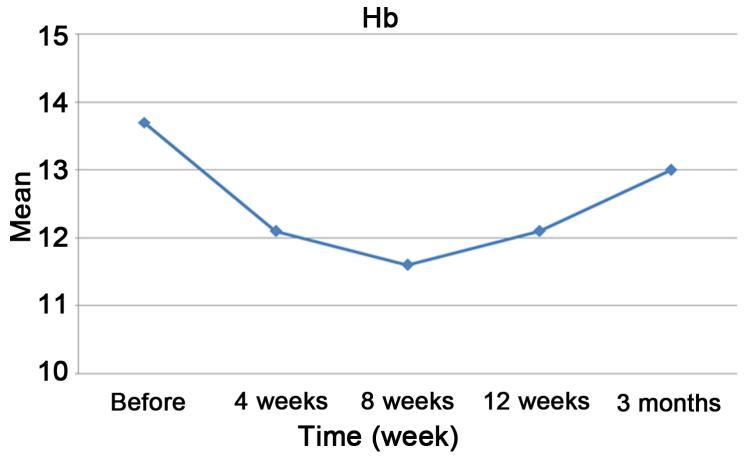

(b)

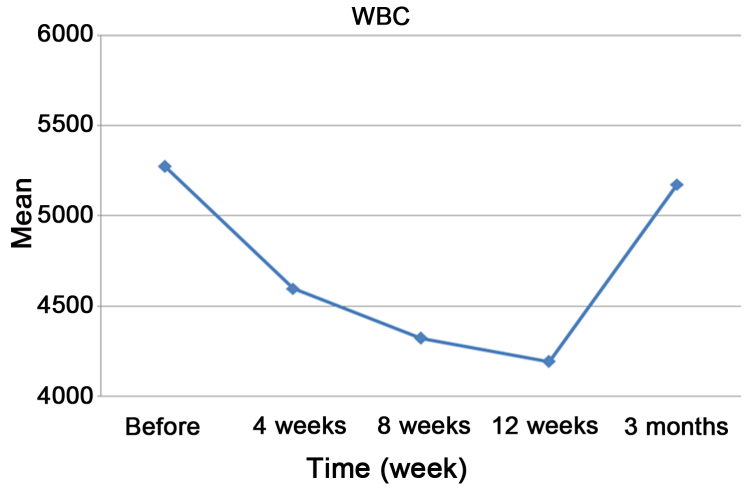

(c)

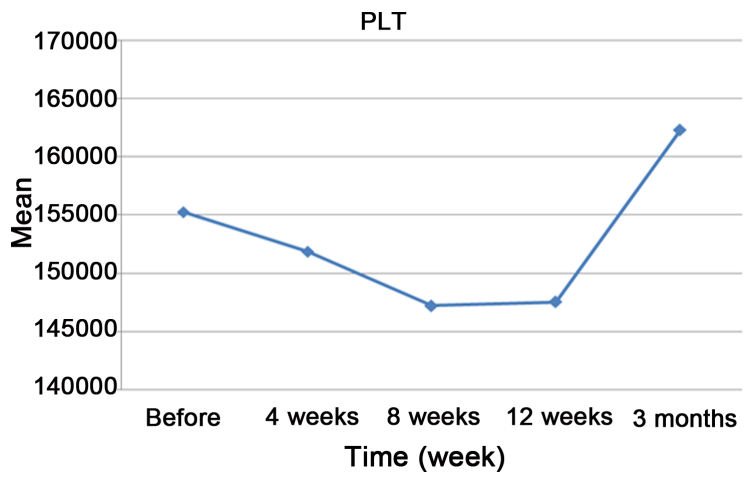

(d)

Figure 4. (a) Shows changes in the liver functions before and after treatment; (b)-(d) shows changes in hemoglobin, white blood cell count and platelets before and after treatment. 


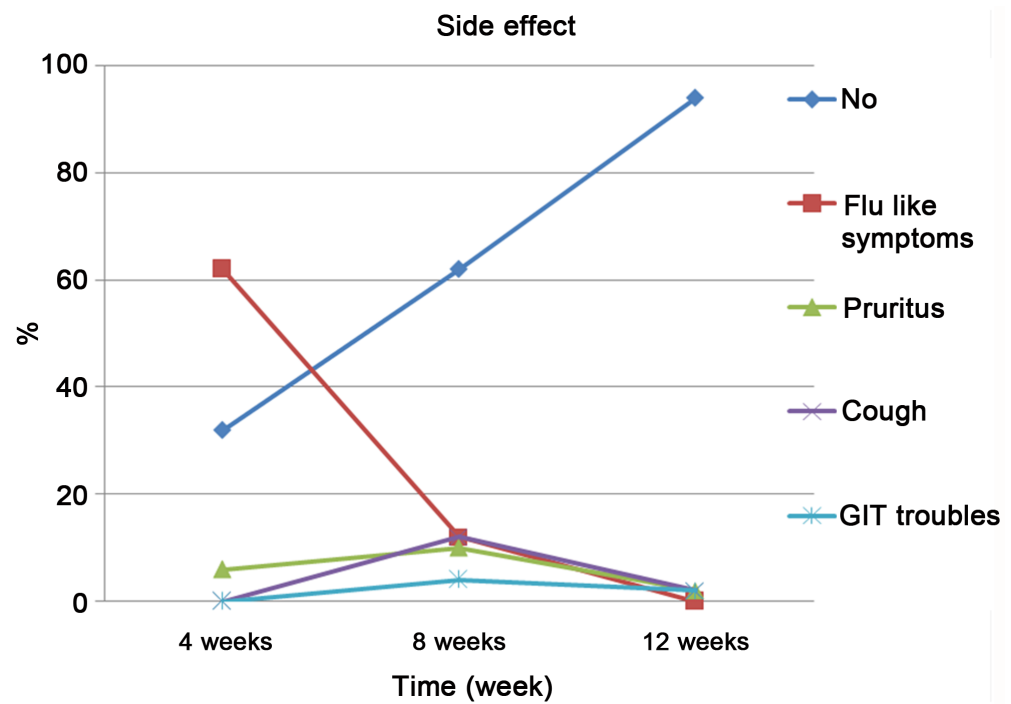

Figure 5. Shows side effects of treatment.

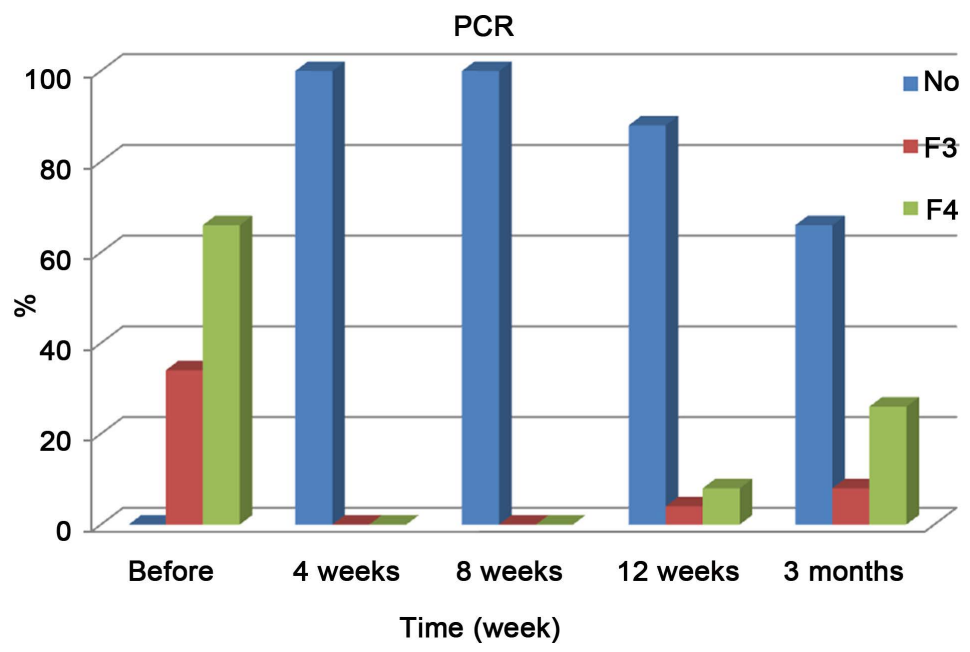

Figure 6. Correlation between response to treatment and stage of fibrosis.

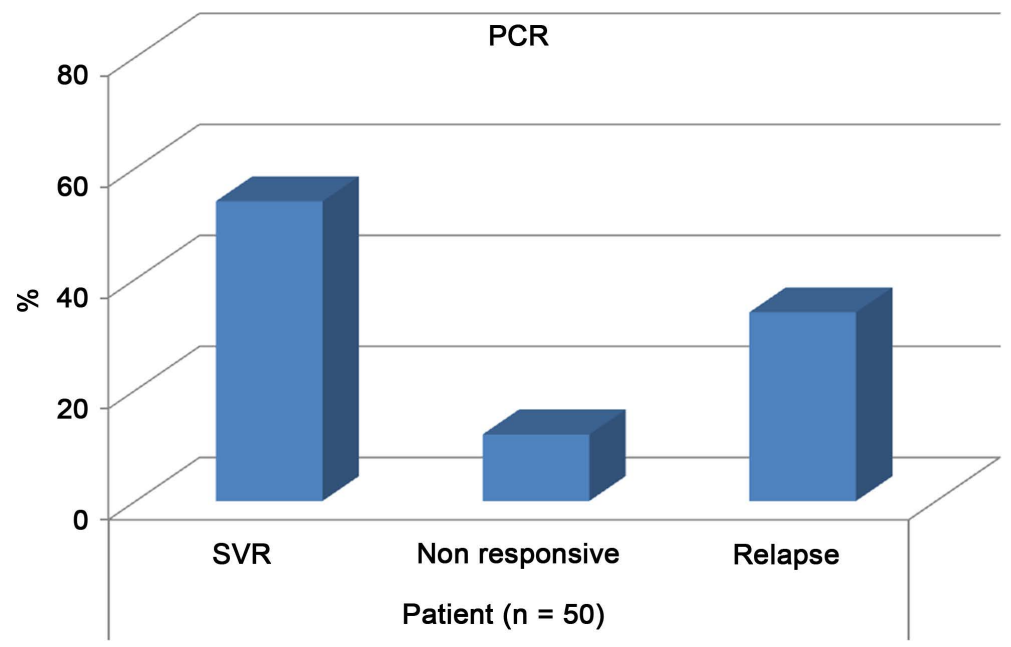

Figure 7. Sustained virological response rate, non-responders and relapser after treatment. 


\section{Discussion}

In this paper we aim to assess efficacy of triple therapy including sofosbuvir as the first NS5B polymerase inhibitor to be available in Egypt with the hope of improving response to treatment of one of the major health problems in Egypt.

In my paper, parenteral antischistosomal injections are the most important risk factors of HCV in Egypt which coincides with Yousra et al. 2013 who postulated that the epidemics of $\mathrm{HCV}$ have been caused by extensive iatrogenic transmission during the era of parentral antischistosomal therapy mass treatment campaigns [4].

Also Pybus et al. 2002 performed study on the prevalence of HCV in Egypt which goes with our paper as it considered antischistosomal injections as the major risk for HCV [5].

Frank et al. 2000 revealed that PAT is one of the important methods for iatrogenic transmission of blood pathogens which goes with our study [6].

In my paper sustained virological response rate to treatment with triple therapy was $54 \%$; non-responders rate was $12 \%$ and relapser rate was $34 \%$, which didn't coincide with NEUTRINO study in which SVR was $90 \%$, and I think in my paper SVR was lower due to high fibrosis as SVR in F3 patients was $88 \%$ which coincided with NEUTRINO study but was lower in those with cirrhosis [7].

In my paper SVR was higher in F3 patient group (88\%) than F4 patient group (66\%).

In my paper there was no significant change during different follow-up periods as regard Serum bilirubin, prothrombin time, albumin, AFP, creatinine, FBS and TSH, which coincides with NEUTRINO study [7].

In my paper there was significant change during different follow-up periods as regard ALT and AST with normalization of liver enzymes in about $78 \%$ of patients' post treatment.

In my paper there was significant decline during different follow-up periods as regard hemoglobin and WBC with significant anemia in about $76 \%$ of patients at the end of treatment and leucopenia in about $40 \%$ of patients which coincides with NEUTRINO study [7].

In my paper side effects to treatment included flu like symptoms in $74 \%$ of patients, pruritus in $18 \%$ of patients, cough in $14 \%$ of patients and GIT troubles in $6 \%$ of patients which coincides with NEUTRINO study [7].

In our study degree of viremia doesn't affect response to treatment which may be explained by small number of patients and this goes with Montserrat et al. 2009 [8].

In Montserrat et al. 2009 stage of fibrosis was not related to response to treatment which doesn't coincide with ours [8].

Montserrat et al. 2009 presented flu like symptoms as the most frequent drawbacks involved $87 \%$ of patients followed by hematological side effects anemia in $28 \%$ of patients and leucopenia in $42 \%$ of patients. This goes with our paper as regard flu like symptoms and leucopenia but percentage of anemia was higher in our study [8]. 


\section{Conflict of Interest}

No conflict of interest was declared by the author.

\section{Financial Support}

No financial support from any institution agency or organization.

\section{References}

[1] Amer, F.A., Gohar, M. and Yousef, M. (2015) Epidemiology of Hepatitis C Virus Infection in Egypt. International Journal of TROPICAL DISEASE \& Health, 7, 119131. https://doi.org/10.9734/IJTDH/2015/15727

[2] Sanaa M.K. (2011) Hepatitis C Virus Genotype 4 Therapy: Progress and Challenges. Liver International, 31, 45-52. https://doi.org/10.1111/j.1478-3231.2010.02385.x

[3] Cure, S., Guerra, I. and Dusheiko, G. (2015) Cost-Effectiveness of Sofosbuvir for the Treatment of Chronic Hepatitis C-Infected Patients. Journal of Viral Hepatitis, 22, 882-889. https://doi.org/10.1111/jvh.12409

[4] Yousra, A.M., Ghina, R.M. and Laith, J.A. (2013) The Epidemiology of Hepatitis C Virus Infection in Egypt: A Systematic Review and Data Synthesis. BMC Infectious Diseases, 13, 288. https://doi.org/10.1186/1471-2334-13-288

[5] Pybus, O.G., Drummond, O.J., Nakano, T., et al. (2002) The Epidemiology and Iatrogenic Transmission of Hepatitis C Virus in Egypt: A Bayesian Coalescent Approach. Molecular Biology and Evolution, 20, 381-387. https://doi.org/10.1093/molbev/msg043

[6] Frank, C., Dipl, G., Mostafa, K.M., et al. (2000) The Role of Parenteral Antischistosomal Therapy in the Spread of Hepatitis C Virus in Egypt. The Lancet, 355, 887891. https://doi.org/10.1016/S0140-6736(99)06527-7

[7] Eric, L., Alessandra, M., David, W., et al. (2013) Sofosbuvir for Previously Untreated Chronic Hepatitis C Infection. The New England Journal of Medicine, 368, 1878 1887. https://doi.org/10.1056/NEJMoa1214853

[8] Montserrat, L., Carmen, C., Javier, M., et al. (2009) Randomized Trial Comparing Pegylated Interferon 2b Versus Pegylated Interferon 2a, Both Plus Ribavirin, to Treat Chronic Hepatitis C in Human Immunodeficiency Virus Patients. Hepatology, 49, 22-310. https://doi.org/10.1002/hep.22598

\section{Scientific Research Publishing}

\section{Submit or recommend next manuscript to SCIRP and we will provide best} service for you:

Accepting pre-submission inquiries through Email, Facebook, LinkedIn, Twitter, etc. A wide selection of journals (inclusive of 9 subjects, more than 200 journals)

Providing 24-hour high-quality service

User-friendly online submission system

Fair and swift peer-review system

Efficient typesetting and proofreading procedure

Display of the result of downloads and visits, as well as the number of cited articles

Maximum dissemination of your research work

Submit your manuscript at: http://papersubmission.scirp.org/

Or contact ojgas@scirp.org 